\title{
AN EXPERIMENTAL ANALYSIS OF CONFABULATION IN A CASE OF KORSAKOFF'S SYNDROME USING A TACHISTOSCOPIC METHOD
}

\author{
BY \\ MARIA WYKE and ELIZABETH WARRINGTON
}

From the Psychological Laboratory, Institute of Neurology, National Hospital, Queen Square, London

Confabulation, in psychiatric and neurological practice, is usually defined (e.g., see Wakeley, 1953) as "the ready narration of fictitious occurrences which the patient believes that he has experienced, and which are not hallucinations but are produced to fill gaps of defective memory, especially in respect of the immediate past; confabulation is considered one of the main signs of Korsakoff's syndrome." In all definitions, there is general agreement that confabulation is the filling-in of a memory gap, and that the patient usually confabulates about material he cannot remember. Confabulation, therefore, is always considered as part of an amnesic syndrome and consequent upon memory defect.

Several interpretations of confabulation have previously been proposed. Pick (1905) believed that in patients with Korsakoff's syndrome there is a fundamental thought disorder, the patient's thinking being dominated by "fixed ideas", and that in such patients there is also increased suggestibility. He proposed that confabulation might arise from a need to rationalize these "fixed ideas", and that this process would be aided by the lack of insight. Therefore, according to Pick, unless one knows about the dominating thoughts in addition to the memory deficits, one cannot explain confabulation in patients with Korsakoff's syndrome.

Van der Horst (1932), on the other hand, postulated a fundamental disturbance of time sense, that is, an inability to correlate experiences in terms of their time relationships. He maintained that, lacking such ability, an individual must have memory deficits. In relating this hypothesis to confabulation, Van der Horst likened confabulation to phantasy, for in phantasy, he said, time as such plays no role. Individuals with a disturbed perception of time may thus be expected to confabulate. He also thought that the confabulated material bore a relationship to personality structure similar to that of the material of dreams.

Williams and Rupp (1938) believed confabulation to result from the interaction of several factors. A basic factor, according to these authors, is a memory disturbance; but it is not the mere existence of retrogressive amnesia, but rather its scope, that is significant in the production of confabulation. The important provocative factor is then a severe disturbance of recent memory. But in addition to amnesia, Williams and Rupp suggested that lack of insight is necessary for the development of confabulation. A personality structure of a particular pattern is also required; and they added that individuals that confabulate have basic tendencies towards introversion, although their behaviour is of extravert type.

On the other hand, Weinstein, Kahn, and Malitz (1956) consider that confabulation cannot be explained on the basis of memory loss, and they propose that confabulation should be regarded as " a mode of adaptation to stress".

That confabulation may depend basically upon altered perception has also been proposed. For example, Grünthal (1923) long ago thought this to be of primary importance. More recently, Talland (1958) showed (with a wide range of perceptual tests) that the psychological disturbances in Korsakoff's syndrome extend beyond impaired memory and learning, and that there are perceptual disturbances that should not be considered secondary to memory disorder. He states that this perceptual impairment is a basic symptom consistently present in the syndrome, although not so apparent (in ordinary clinical circumstances) as the amnesic phenomena. However, he does not consider the memory defect, or the confabulation, to result from the basic perceptual disorder; on the contrary, he thinks that the perceptual and amnesic disorders may be a joint manifestation of the same underlying disturbance. In a later paper, Talland and Ekdahl (1959) have described the results of an analysis of memory for narrative material, and the series of distortions in serial reproductions, in a group of 
patients with Korsakoff's syndrome associated with alcoholism. In experimentally-created conditions of ambiguity and delay, they found that some normal patients distorted and elaborated stories in much the same manner as their patients with Korsakoff's syndrome. They therefore suggest that confabulation may more properly be regarded as an effect of a "state of indirection" existing in patients with Korsakoff's syndrome, rather than as a primary symptom of the disease. However, it is not clear what this "state of indirection" implies.

In contrast to these views, Kral (1956) stated that there are no perceptual abnormalities in Korsakoff's syndrome. Clinical observations, according to this author, show that patients suffering from a chronic amnesic syndrome are capable of well-integrated perceptions, both from the environment and from within their own bodies. He suggests that Hartmann's (1927) experiments prove this point. Hartmann was able to demonstrate that under hypnosis there were traces of registration of new material in patients with Korsakoff's syndrome, and Kral regarded this as evidence of preservation of perceptual mechanism.

In the present paper, an attempt is made to analyse the confabulatory process in a case of Korsakoff's syndrome by tachistoscopic presentation of material, in order to determine the circumstances in which confabulation appears.

The purpose of the study is to decide to what extent confabulation is a primary symptom of Korsakoff's syndrome or if it is consequent upon memory defects.

\section{Case Study}

P. R. (Case 77971), a housewife aged 48 years, was admitted to the National Hospital complaining of epigastric discomfort, anorexia, and morning vomiting for one month.

Three years previously, while in Nigeria, she had suffered from an illness diagnosed as peripheral neuritis that was associated with excessive intake of alcohol (whisky). Eighteen months after this illness, she had for the first time recurrent attacks of abdominal pain and vomiting. On that occasion the liver was found to be enlarged. In each instance, the attacks were associated with an increased intake of alcohol.

Three weeks before her admission to the National Hospital she had a severe attack of vomiting. Examination then showed left internal strabismus, and left facial weakness. In addition, she was confused and disorientated, and on two occasions she had had episodes of hallucinations, seeing soldiers drilling in the garden and friends entering her room during the night. She was treated with large doses of vitamin B complex.

On examination on admission to the National Hospital, she was found to be completely disorientated in time and place, and she confabulated freely.
Visual acuity was normal in each eye, and the visual fields were full. The pupils were normal in size, and reacted briskly to light and on convergence. External ocular movements were normal, but there was coarse nystagmus on looking to right and left. Apart from some facial asymmetry without obvious facial weakness, the remaining cranial nerve functions were normal.

There was a fine, irregular tremor of the outstretched fingers but no weakness of any limb. The tendon reflexes were sluggish in the arms; the patellar reflexes and the left ankle jerk were absent. Appreciation of pinprick was absent over the feet and lower parts of 0 both legs and over the hands and forearms.

The tongue was smooth and glossy. There was some abdominal tenderness, and the liver was palpable below the right costal margin; there was no ascites or oedema.

The results of liver function tests were mildly abnormal, e.g., thymol turbidity 3 units, serum bilirubin $0.3 \mathrm{mg}$./ $100 \mathrm{ml}$., alkaline phosphatase 7.6 (K-A units), but other biochemical and haemotological studies disclosed no abnormalities, except for a sedimentation rate of $29 \mathrm{~mm}$. in one hour. The blood Wassermann reaction was negative.

A diagnosis of alcoholic Korsakoff psychosis, associated with peripheral neuritis, was made. The in patient was treated with intravenous "parentrovite" $(10 \mathrm{ml}$. daily), which produced gradual improvement in some respects. At the time of her discharge from the $\bar{B}$ National Hospital, four weeks after first being given th $\bar{\Phi}$ "parentrovite" injections, the sensory impairment if the legs had disappeared, as had the nystagmus anc abdominal tenderness. However, the patient remaine $\Phi$ confused and disorientated, and continued to cono $\Phi$ fabulate. She was therefore transferred to a psychiatrieg unit, where she remained for a further seven months.

At the time of her discharge from this latter unit ske was well orientated, and there was no clear evidence of residual memory impairment although she showed a tendency to repeat requests, to reiterate observations, and to employ stereotyped phrases all in a manner suggestive of a defect of recent recall.

\section{Psychometric Assessment}

The patient was first seen in the Psychological Department six days after admission to the National Hospital. Thereafter, she was examined at regular intervals until her discharge from the National Hospital to the psychiatric unit.

When first seen, the patient showed a marked amnesic syndrome. There was fluctuating disorientation for place and person, but orientation in time was better, in that she usually knew the year and the month, was orientated for time of day, and also knew her age. Memory for recent events was extremely poor, and she confabulated freely. Her thought processes were nct markedly altered, though explanation of proverbs was somewhat concrete and flighty, and she displayed some evidence of fixed ideas. She was also very suggestible, and lacked insight.

*A multivitamin preparation of Vitamins Ltd., London. 
Psychometric tests gave uneven results. Her vocabulary score was at the high-average level. Scores in other tests were in the average to high-average range, except in arithmetic and digit symbol, in which the scores were below this level. Her intelligence quotient on the full scale was 96.

There was no evidence of faulty visual perception, and the patient identified objects and interpreted pictures quite accurately.

When reproducing designs from memory (Bender, Curran, and Schilder, 1938), she showed marked falsification and reduplicating paramnesia. She also perseverated from early to late designs. When asked to recall associations between word pairs, she frequently substituted another word. Her associations then usually involved familiar associations or combinations of two words belonging to different pairs.

Her capacity to form logical memories from stories read to her was grossly impaired. She consistently introduced new material that usually bore some relation to her fixed ideas and she also perseverated from one story to another. In all respects her performance in intelligence and memory tests was very similar to that reported by Victor, Herman, and White (1959) in his psychological study of the Korsakoff syndrome in cases of Wernicke's encephalopathy.

\section{Tachistoscopic Tests}

Two types of tachistoscope were used, a new Dodge type (Warrington, 1960), and a modified version of the “dazzle" tachistoscope (Ettlinger, 1960).

Test Materials.-The material presented to the patient in the Dodge type of tachistoscope was divided into three categories:

(1) Simple, familiar geometrical figures, comprising a circle, a square, a rectangle, and a four-pointed star (Fig. 1). Each figure was presented both as a whole (items 1-4), and also as partial figures (items 5-8).

(2) Complex, meaningful forms comprising line drawings of common objects such as a house, a face, and a flower (Fig. 1). These were presented in two ways: with some details (items $9,13,17$ ), and without details (items 10,14,18). They were also presented as complete and as incomplete (items 11, 12, 15, 16, 19, 20) figures.

(3) Ambiguous figures, as shown in Fig. 1 (items 21-23).

Instructions to Patient.-The instructions given to the patient were as follows:

"I want you to look at the small cross in the centre of the screen. When I say ' ready' a drawing will appear on the screen for a very short time. I want you to tell me exactly what you see. It is important to tell me what you actually see: I do not want you to guess. I will also want you to make me a drawing of what you see."

Procedure.-The following procedure was employed. The patient was shown the stimulus cards in each of the above categories in random order. Each figure was presented in an ascending series of exposure times, until the recognition threshold was attained. The criterion for recognition threshold in this patient was taken as the minimum duration of exposure needed for relatively accurate recognition of the figure being presented. The figures were then presented several further times, with increasing durations of exposure over the threshold time. The patient was asked to make a fresh drawing of the figure after each exposure.

With the dazzle tachistoscope two pictures were also presented (see Fig. 1, items 24, 25). The patient was told that the pictures on the screen would at first be too dim to be seen but that they would become progressively brighter and clearer. The filter in the dazzle tachistoscope was adjusted so that a black and white picture was invisible against the background at the beginning of the tests. The intensity of the illumination was then increased by standard steps until the picture was plainly visible. The patient was asked to respond as soon as she could distinguish any darkness or shadow against the background and again as soon as she could identify the content of the picture.

\section{Results}

Threshold.-With the Dodge tachistoscope, the threshold exposure time for recognition of all the pictures in 92 trials was between 25 and $32 \mathrm{~m}$.sec. This is within the range of variation found by Warrington (1960) in normal subjects, using identical pictures on the same machine.

With simple familiar geometrical figures (category 1) recognition was accurate, as was immediate reproduction of the figures in drawings. Sometimes, with exposure durations of less than $40 \mathrm{~m} . \mathrm{sec}$., the patient reported seeing a half-figure as complete but this was not consistent.

With complex, meaningful figures (category 2) the responses varied considerably; but they may be classified into four main groups.

(1) When pictures were shown complete and with details added, verbal responses were accurate, as was immediate reproduction in drawings.

(2) When pictures were shown complete but without detail, the responses revealed elaboration in both verbal description and in pictorial reproduction, or else the omitted details were completed. These responses were elicited with exposure times above $40 \mathrm{~m}$.sec. An example of this type of response is shown in Fig. 2, containing the patient's own sketches in response to presentation of item 14 in Fig. 1.

(3) When half-pictures with detail were shown, the verbal responses were accurate but the patient's drawings did not correspond exactly to the material viewed. Thus a half-face was called "half-face" but it was drawn as a profile, as shown in Fig. 3. These responses were also made at exposure times greater than $32 \mathrm{~m} . \mathrm{sec}$.

(4) When half-figures without detail were presented, responses were often inaccurate. In addition, the reproduced drawings frequently did not accord 

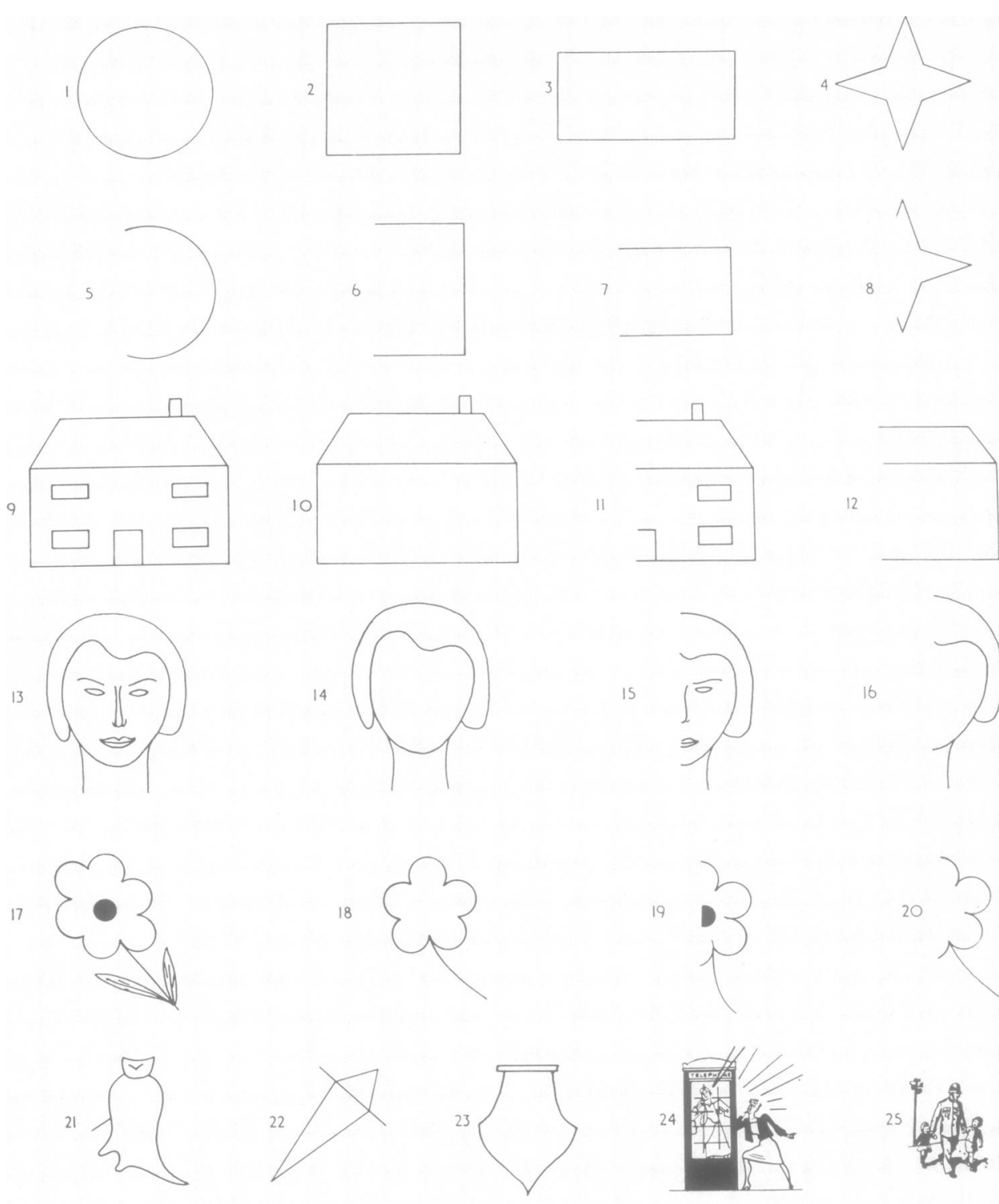

FIG. 1.-Material presented in the tachistoscope. Items 1-23 were shown in the Dodge tachistoscope. Items 24 and 25 were shown in the "dazzle" tachistoscope.

with the verbal report of what was seen. Thus item 10 in Fig. 1 was called a "writing table" but drawn as a square. The half-face (item 16 in Fig. 1) was reported as a half-face, but was drawn (see Fig. 4) as a complete face at an exposure time of $40 \mathrm{~m} . \mathrm{sec}$. and as a profile at $50 \mathrm{~m} . \mathrm{sec}$. The halfflower (item 19 in Fig. 1) was called " half a flower" and drawn as such, but details were added in the pictorial reproduction.
With the ambiguous figures (category 3) gross elaboration was evident at all exposure times, even up to one second. The reproduction drawing of the material seen usually corresponded with the verbal 의 report. For example, item 22 in Fig. 1 was called " a man on a swing" at $32 \mathrm{~m} . \mathrm{sec}$. exposure; at $40 \mathrm{~m} . \mathrm{sec}$. it was described as a "swing at an angle"; at $50 \mathrm{~m} . \mathrm{sec}$. N as " rope and wood like a swing" with " a body half off". The patient's drawings, corresponding 

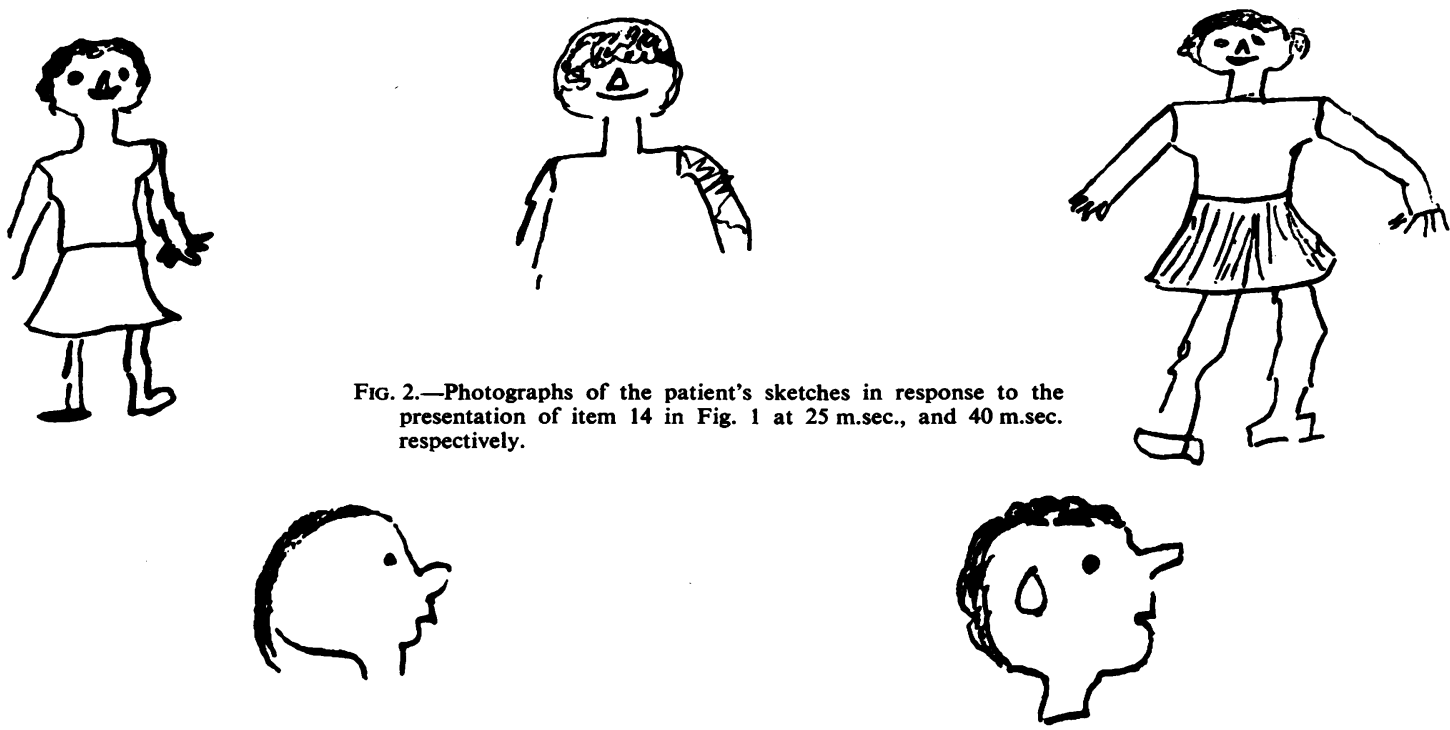

FIG. 3.-Photographs of the patient's sketches in response to the presentation of item 15 in Fig. 1 at $32 \mathrm{~m} . s e c$. (on left) and 40 m.sec. (on right).
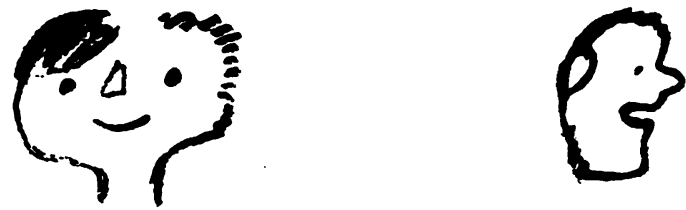

FIG. 4.-Photographs of the patient's sketches in response to the presentation of item 16 in Fig. 1 at $40 \mathrm{~m} . \mathrm{sec}$. (on left) and at $50 \mathrm{~m} . \mathrm{sec}$. (on right).
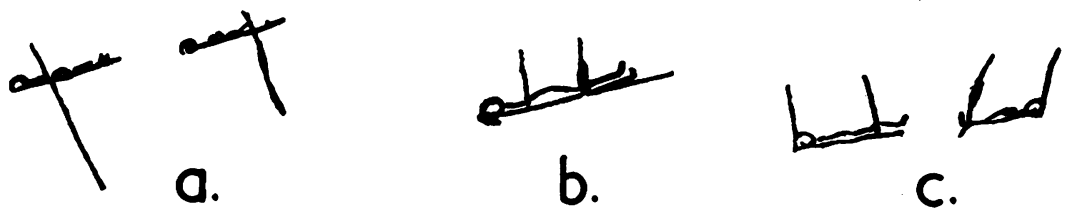

C.
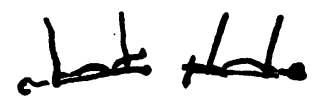

Fig. 5.-Photographs of the patient's sketches in response to the presentation of item 22 in Fig. 1 at 25 m.sec. (a), 32 m.sec. (b), 40 m.sec. (c), and 50 m.sec. (d).

to each of these descriptions, are shown in Fig. 5.

With the dazzle tachistoscope, the patient reported seeing pictures even when the intensity of illumination was such as to make this impossible. Confabulation was marked at low intensities of illumination, but decreased as illumination became brighter. An example of this type of progressive change in the responses follows, the picture presented being item 25 in Fig. 1.
(1) With the picture invisible, "it is a mediaeval dress, with feathers in the hat."

(2) The intensity of illumination was then increased in a series of steps, each step resulting in the following sequence of responses:-

(a) "A big black arrow is pointing towards you. A man's head is at the bottom."

(b) "Still the man's head. Above it is a figure like a great big bird. It is an arrow." 
(c) " Lots of figures. It looks like looking down into an auditorium."

(d) "Looks like a mass of people."

(e) "A sort of emblem. A donkey or a horse. A man on a horse."

$(f)$ "A man standing. A little boy sitting down, and a little girl sitting in a chair behind them."

(g) "A man holding a little boy with his right hand. There are two chairs. The boy is facing one way. They are walking hand-in-hand."

(h) "A little boy holding hands. The man is in a helmet. The little boy is talking to him, but I see a little girl in a chair."

(3) With maximum illumination, "I see a man walking towards me, and a little boy holding his hand. The little girl is coming behind. In the background there is a tree, and a lot of people like an audience."

With a second picture (item 24, Fig. 1), a similar series of responses was given, confabulation being greater when the picture was less intensely illuminated. Neither with the first nor with the second picture did the patient at any time complain of difficulty in seeing the figures, even at very low intensities of illumination. Instead, descriptive responses were produced immediately when requested, irrespective of the intensity of illumination and even when it was zero.

\section{Discussion}

In this study the patient produced elaborated descriptions and drawings of meaningful figures when these were presented as half-figures, or as outline figures without added detail. This elaboration occurred both in verbal description and in pictorial reproduction of the material, it appeared at durations of exposure well above the perceptual threshold, and it was consistently present with repeated exposures.

Elaboration was most marked when the figures presented were ambiguous, especially when they were presented in the dazzle tachistoscope. In the latter circumstances, responses were more complex when the pictures were less likely to be seen clearly, and their elaboration decreased as the level of illumination increased, until more or less accurate identifications were made at high intensities of illumination.

It seems reasonable to describe these responses as perceptual confabulation, as the patient reported seeing material bearing no relation whatsoever to the visual stimuli presented, and made ready answers without regard to reality. As the patient believed that she had actually seen the things that she reported and drew, her responses cannot be considered as mere invention.

The patient's completion of half-figures into whole figures, and her elaboration of details when reproducing non-detailed figures, may be regarded as lesser degrees of the same process.

It is now necessary to consider to what extent the responses of this patient, responses involving completion, elaboration, and frank confabulation, are dependent upon perceptual deficits or upon memory loss, or whether they are manifestations of some other underlying disturbance.

It is hardly necessary to stress the fact that the phenomena cannot result from a perceptual deficit, for the patient was able to identify complete meaningful figures at exposure times within the range required by normal subjects. In the tachistoscopic study of her confabulation, all the pictures were presented at exposure times above threshold; and on several occasions she was capable of describing a figure correctly, although she produced marked elaborations in her drawings of it. It may be that there are subtle alterations of tachistoscopic perception in this patient that might be revealed in tests such as those employed by Talland (1958) But Talland indicated that the perceptual disorder $\$$ of this order that he found in patients witlo Korsakoff's syndrome could not be the basis of $Z$ their disorders of memory or of their confabulation.

Further, this patient's performance cannot be attributed to a defect in immediate memory Psychometric studies showed that her memory spat for visually presented figures (and for digits) was adequate, and that reduplicating paramnesia occurred only in successive reproductions. In the present tachistoscopic investigations, all figures were described and drawn immediately after presentation in the Dodge apparatus, and every demand for reproduction was always preceded by a fresh exposure of the picture. With the dazzle tachistoscope, the responses were recorded while the patient was actually watching the screen.

These observations suggest that confabulation may be specially induced by visual stimuli in appropriate circumstances; in other words, its production is a manifestation of a particular psychological " set ". That confabulation can be facilitated by certain conditions has previously been pointed out by Pick (1905), who noted that it could be provoked at will by appropriate interrogation of patients with Korsakoff's syndrome, and similarly, it could be directed along any desired channel. If this be so, confabulation may in reality be a basic symptom of the disease processes occurring in Korsakoff's psychosis, and not merely represent a phenomenon secondary to memory impairment. 
Many reports in the literature (e.g., Kral, 1956) point out that there is no invariable relation between memory loss and confabulation. However, the converse does obtain, viz., that there is no confabulation without impairment of memory. But this latter fact does not imply that a memory deficit is the causative factor in confabulation, and it might be that a memory defect merely creates a " set " within which the appearance of confabulation is facilitated. In this respect, it is relevant to note that in 1901 Bonhoeffer attempted to identify two kinds of confabulation. He described one type, occurring during alcoholic delirium, that he considered to be a direct consequence of memory deficit. For the other type, he stated that a certain degree of attention (Attentheit) and "psychic alertness" (geistige Regsamkeit) must be present, and he pointed out that in this case confabulation may involve more than is required by the mere necessity of filling a memory gap.

It is important to enquire what are the conditions capable of facilitating a confabulatory response. In this respect, it seems that a confabulatory response may appear as the result of the interaction of two factors. One factor is represented by a particular stimulus set. Thus, in experimental situations in which there is a "set of expectancy", e.g., when the patient is " set " to see something by telling him that he will see something, plus the presentation of certain incomplete and ambiguous stimuli, patients with Korsakoff's syndrome may be induced to confabulate, as in the present study.

The second factor is more difficult to identify, and as pointed out earlier, various views as to its nature has been proposed. It is possible that increased suggestibility (Pick, 1905) a specific personality make-up (Williams and Rupp, 1938) or a social process (Weinstein et al., 1956) may play a part in the development of confabulation. At present, there is little of real significance to be said about the explanation of this second factor in the genesis of confabulation, and the present study throws no light on its psychological nature.
Nevertheless, the findings in this case indicate that confabulation is a primary symptom of Korsakoff's syndrome, and should not be regarded merely as a consequence of memory disturbance.

\section{Summary}

Different interpretations of the phenomenon of confabulation are reviewed.

An experimental analysis of confabulation in a case of Korsakoff's syndrome is reported.

The facilitation of confabulation by tachistoscopic presentation of particular types of visual stimuli is reported.

It is suggested that confabulation should be considered a primary symptom of Korsakoff's syndrome and not a result secondary to memory defect.

We should like to thank Dr. Denis Brinton for his permission to report this case, to Dr. G. Wakefield for his help with its clinical aspects, and Professor O. L. Zangwill for his advice and his help in translating the German literature.

We are also grateful to Mr. Pricket, of the Department of Photography of the National Hospital, for the photographs.

\section{REFERENCES}

Bender, L., Curran, F. J., and Schilder, P. (1938). Arch. Neurol. Psychiat. (Chicago), 39, 482.

Bonhoeffer, K. (1901). Die akuten Geisteskrakheiten der Gewohnheitstrinker, pp. 124-136. Fischer, Jena.

Ettlinger, G. (1960). J. ment. Sci. In press.

Grünthal, E. (1923). Mschr. Psychiat. Neurol., 53, 89.

Hartmann, H. (1927). Wien. klin. Wschr., 40, 1507.

Horst, L., van der (1932). Mschr. Psychiat. Neurol., 83, 65.

Kral, V. A. (1956). Ibid., 132, 65.

Pick, A. (1905). Neurol. Centralbl., 24, 509.

Talland, G. A. (1958). J. nerv. ment. Dis., 127, 197.

Talland, G. A. (1958). J. nerv. ment. Dis., 127,

Victor, M., Herman, K., and White, E. (1959). Quart. J. Stud. Alcohol, 20, 467.

Wakeley, C. (Ed.) (1953). The Faber Medical Dictionary. Faber \& Faber, London.

Warrington, Elizabeth (1960). Completion of Visual Forms Across Hemianopic Field Defects. Ph.D. Thesis, University of London. Weinstein, E. A., Kahn, R. L., and Malitz, S. (1956). Psychiatry, 19, 383.

Williams, H. W., and Rupp, C. (1938). Amer. J. Psychiat., 95, 395 . 